\title{
Assessment of Sexual Troubles in Egyptian Women with Female Genital Mutilation
}

Case

Study

\author{
Mohamad A. Abdelhafeez, Mohamad S. Salem, Manal G. Eisa, Amr A. Reyad \\ Department of Obstetrics and Gynecology, Faculty of Medicine, Ain-Shams University, Cairo, \\ Egypt
}

\begin{abstract}
Background: Female genital mutilation (FMG) is a national concern. It is known from previous researches that it causes complications as shock, hemorrhage, infections and sexual dysfunction. In spite of that, people still insist on practicing this tradition on their daughters regardless the consequences to avoid future adultery.

Aim: This study aimed to further assess the effect of FGM on the prevalence of sexual troubles among Egyptian women.

Materials and Methods: This case control study comprised 500 sexually active women in 2 groups : 250 with FGM (case group) and 250 without FGM (control group) at El-Demerdash Maternity Hospital. All the study participants were asked to answer the Arabic translated version of Female Sexual function Index (FSFI) questionnaire and the individual domain scores for pain, arousal, lubrication, orgasm, satisfaction and overall score of FSFI were calculated.

Results: The two groups were comparable in most demographic characteristics. There were no statistical differences in the mean desire score and the mean pain score (+/- standard deviation) between the two groups. However, the mean scores for arousal, lubrication, orgasm and satisfaction and so the overall score showed significant differences between the two groups with the group with FGMs scoring much less.

Conclusion: FGM causes sexual dysfunction, not in the form of decreased desire as traditions aimed for, but on the contrary, in the form of anorgasmia (not being able to end the stimulated desire to reach a latent period desire free) which leads to pelvic congestion and psychological frustration and depression.
\end{abstract}

Key Words: Anorgasmia, clitoris, female genital mutilation, FSFI, sexual dysfunction orgasm, sexual function

Received: 07 December 2019, Accepted: 17 January 2020

Corresponding Author: Manal G. Eisa, Department of Obstetrics and Gynecology, Faculty of Medicine, Ain-Shams University, Egypt,Tel.: 01009201201, E-mail: manaleisa6@gmail.com

ISSN: 2090-7265, May 2020, Vol.10, No. 2

\section{INTRODUCTION}

Female genital mutilation (FGM) according to the WHO is partial or total removal of the female genital organs for non-medical causes ${ }^{[1]}$. The United Nation Children's Emergency Fund (UNICEF) estimated that $92 \%$ of married women in Egypt aged between 15 and 59 years have been mutilated ${ }^{[2]}$ whether by medical staff or relatives in spite of being illegal because of wrong cultural or religious beliefs ${ }^{[3,4]}$. Jame Nedal, the United Nation Population Fund Representative in Cairo, said that the rate is so high that one fourth of the cases worldwide are in Egypt. FGM has reached such epidemic proportions because of the traditional false belief that it stops women from becoming adulterous or have extra marital $\operatorname{sex}^{[5]}$. Many African Muslims and Christians practice this abuse although not ordered by any of the true sayings of the prophet, the Holy Quran, or the bible ${ }^{[6]}$. An important research done by Dr. Sharifa Sibiani and Professor Abdulrahim Rouzi from King Abdul-Aziz University Hospital in Jeddah proved that women with FGM were not likely to have less desire than those without FGM and were not likely to suffer more pain during coitus. However, mutilated ladies were less likely to be able to reach the orgasmic phase after the excitation phase or anorgasmia ${ }^{[7]}$. Anorgasmia, according to the $\mathrm{WHO}$ is the recurrent difficulty, delay, or total absence of orgasm after sufficient sexual stimulation ${ }^{[8]}$. On the contrary, women without mutilation experienced less difficulty in culminating their arousal phase through orgasm ${ }^{[7]}$. Masters and Johnson identified the clitoris, the analogue of the erectile tissue in males, as the center of orgasm in women ${ }^{[9]}$. Orgasm and sexual gratification has been associated with nerve endings in clitoris. However, although the cervix has a rich nerve supply, there is no scientific evidence that it plays a role in the sexual response ${ }^{[10]}$. However, sexual desire in both sexes is hormonally controlled and the way to avoid it is by castration Instead of external genital cutting ${ }^{[11]}$.

\section{PATIENTS AND METHODS}

This case control study was conducted at El-Demerdash 
Maternity Hospital, Ain-Shams University, Cairo, Egypt between March 2018 and April 2019 and comprised 500 sexually active women in 2 groups: 250 with FGM (case group) and 250 without FGM (control group) .

Inclusion criteria: Healthy, Egyptians, married, non-pregnant and ages between 20 and 40 years old.

Exclusion criteria: Non Egyptians, virgins, pregnant ladies, ages less than 20 years old and more than 40 years with debilitating disease.

All the study participants were interviewed during their visits to El-Demerdash Maternity Hospital after explaining our research objective and aim and were asked to answer the documented Arabic translated version of Female Sexual Function Index (FSFI) questionnaire. FSFI questionnaire is a brief, multidimensional, validated international tool for assessment of sexual function. The participants agreed to answer the questionnaire with complete confidentiality, after their oral approval and written consents and after approval of the board of research ethics in Ain-Shams University.

This questionnaire consists of 19 questions concerning sexual functions : 2 questions measuring domains of libido, 4 questions for arousal, 4 questions for lubrication, 3 questions for orgasm, 3 questions for satisfaction and 3 questions for pain. Each question is given a score of 0 or 1-5. Then, each domain score and the total score is calculated ${ }^{[8]}$.

\section{STATISTICAL ANALYSIS:}

The collected data has been tabulated and statistically analyzed using SPSS program (Statistical Package for Social Sciences) software version 20.0.

\section{RESULTS}

There was no statistically significant difference between both groups regarding age, diseases, smoking habits, husband's diseases and medications as shown in Table 1.

All ages were between 30-35 years with the mean age of women with FGM was 31.68 (SD +/- 5.26) versus 32.1 (SD +/-4.84) for those without FGM with p-value 0.344. Concerning co-morbidities, $p$-value was 1.000 which is statistically insignificant.

However, concerning level of education, high education level was $28.8 \%$ for the group with FGM versus $36.4 \%$ for those without FGM which is statistically significant with $p$-value 0.002 . Also, number of children showed statistically significant difference with $p$-value less than 0.001 .

There was no statistically significant difference between the two groups in the desire and pain scores as shown in Table 2.

In the group with FGM, the desire score was 7.01 (SD +/-0.98) versus $7.08(\mathrm{SD}+/-0.91)$ in the group without FGM with $p$ value 0.389 . The pain score in the group with FGM was 4.92 (SD +/-0.72) versus $4.97(\mathrm{SD}+/-0.69)$ in the group without FGM with $p$ value 0.432 .

However, table 2 and Figure 1 showed that there was statistically significant difference between the two groups concerning the arousal score, lubrication score, orgasm score and satisfaction score where the group with FGM scored much less.

Table 1: Comparison between cases (FGM) and Controls (No FGM) as regard spouse socio- demographic characteristics:

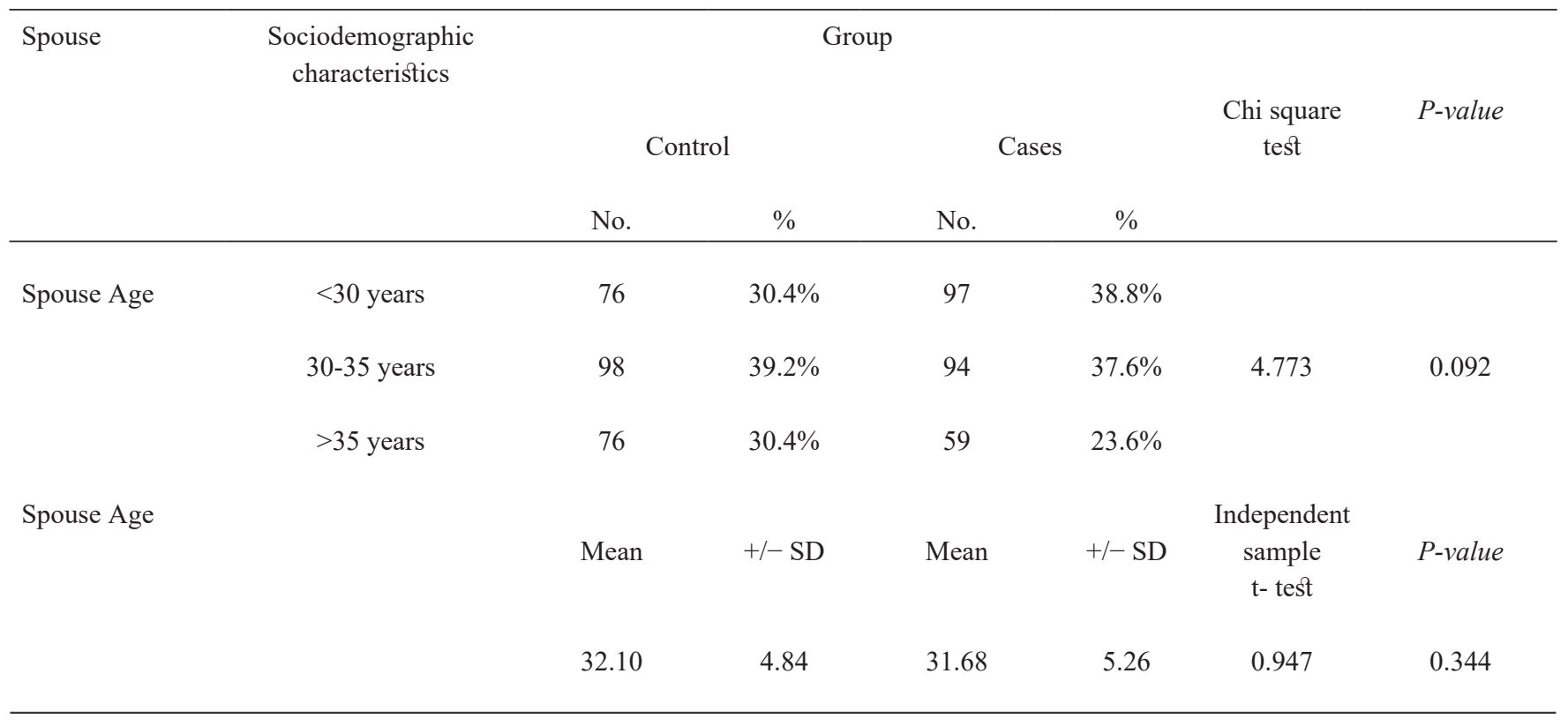




\begin{tabular}{|c|c|c|c|c|c|c|c|}
\hline \multirow{3}{*}{$\begin{array}{l}\text { Spouse } \\
\text { Education }\end{array}$} & School education & 7 & $2.8 \%$ & 25 & $10.0 \%$ & 12.343 & $0.002 * *$ \\
\hline & Diploma & 152 & $60.8 \%$ & 153 & $61.2 \%$ & & \\
\hline & High education & 91 & $36.4 \%$ & 72 & $28.8 \%$ & & \\
\hline \multirow[t]{3}{*}{ Comorbidities } & Absent & 241 & $96.4 \%$ & 242 & $96.8 \%$ & 0.309 & \\
\hline & Hypertension & 6 & $2.4 \%$ & 6 & $2.4 \%$ & $\mathrm{FE}(\#)$ & 1.000 \\
\hline & Gestational Diabetes & 3 & $1.2 \%$ & 2 & $0.8 \%$ & & \\
\hline \multirow[t]{5}{*}{ No of children } & No children & 28 & $11.2 \%$ & 21 & $8.4 \%$ & & \\
\hline & 1 child & 53 & $21.2 \%$ & 22 & $8.8 \%$ & & \\
\hline & & & & & & 49.258 & $<0.001 * *$ \\
\hline & 2 children & 104 & $41.6 \%$ & 67 & $26.8 \%$ & & \\
\hline & 3 or more children & 65 & $26.0 \%$ & 140 & $56.0 \%$ & & \\
\hline
\end{tabular}

** Highly statistically significant if $P<0.01$

(\#) Fisher Exact test was used as $(20.0 \%)$ of the cells or more have an expected count less than 5

Table 2: Comparison between cases (FGM) and Controls (No FGM) as regard Components FSD

\begin{tabular}{|c|c|c|c|c|c|c|}
\hline \multirow{3}{*}{$\begin{array}{l}\text { Female Sexual } \\
\text { Dysfunction } \\
\text { Components }\end{array}$} & \multicolumn{4}{|c|}{ Group } & \multirow{3}{*}{$\begin{array}{l}\text { Independent } \\
\text { sample t-test }\end{array}$} & \multirow{3}{*}{$P$-value } \\
\hline & \multicolumn{2}{|c|}{ Control } & \multicolumn{2}{|c|}{ Cases } & & \\
\hline & Mean & $+/-\mathrm{SD}$ & Mean & $+/-\mathrm{SD}$ & & \\
\hline Desire & 7.08 & .91 & 7.01 & .98 & 0.863 & 0.389 \\
\hline Arousal & 5.49 & .61 & 3.16 & .82 & 36.043 & $<0.001 * *$ \\
\hline Lubrication & 5.02 & .51 & 2.93 & .66 & 39.911 & $<0.001 * *$ \\
\hline Orgasm & 5.01 & .55 & 2.97 & .79 & 33.536 & $<0.001 * *$ \\
\hline Satisfaction & 5.35 & .58 & 2.81 & .86 & 38.691 & $<0.001 * *$ \\
\hline Pain & 4.97 & .69 & 4.92 & .72 & 0.786 & 0.432 \\
\hline FSD & 32.94 & 2.97 & 23.80 & 3.04 & 33.959 & $<0.001 * *$ \\
\hline
\end{tabular}

** Highly statistically significant if $P<0.01$ 


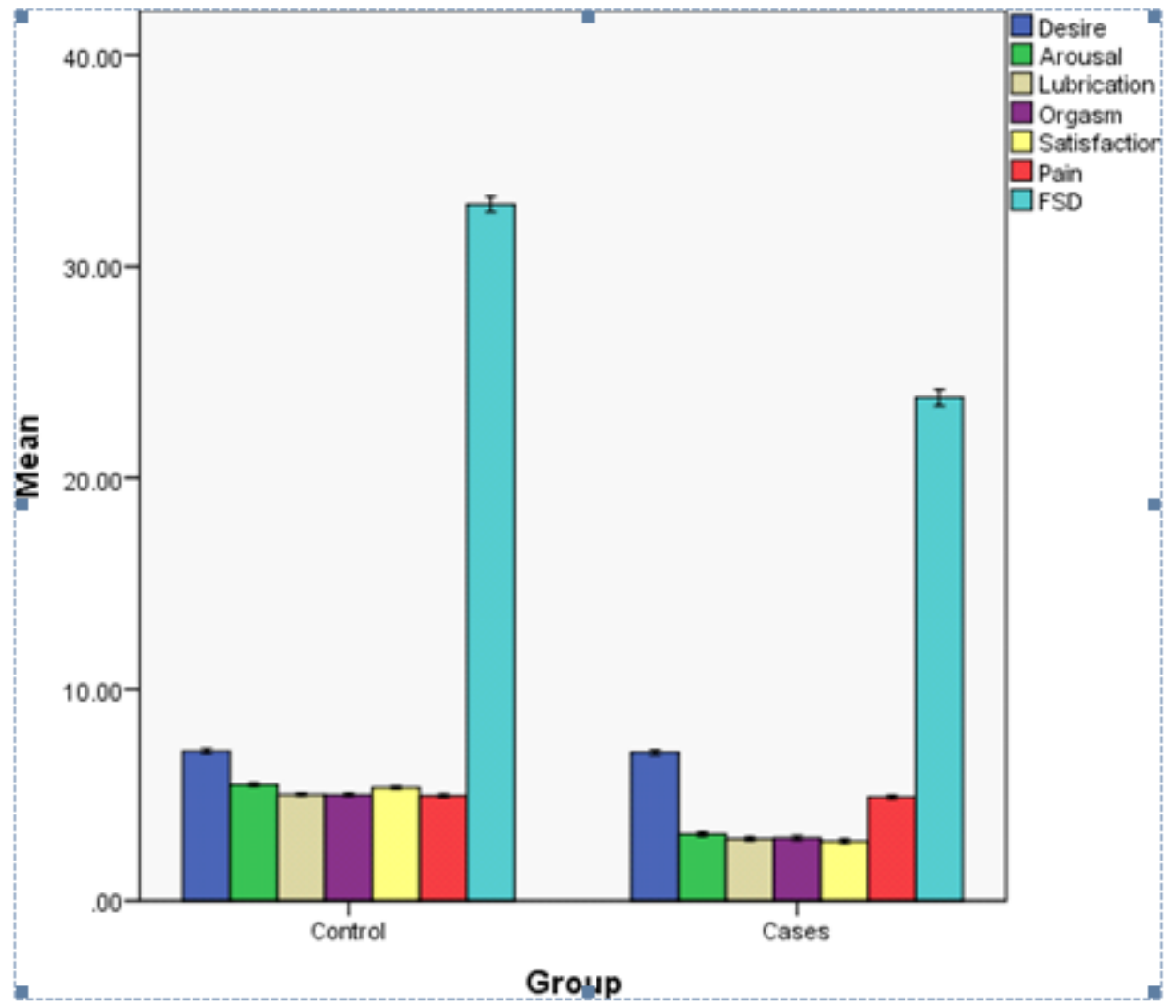

Fig. 1: Comparison between cases (FGM) and Controls (No FGM) as regard Components FSD

\section{DISCUSSION}

Female sexual dysfunction is defined as any disorder affecting any component of sexual function whether desire, arousal, lubrication, satisfaction, orgasm, sexual pain or any personal distress during the sexual act ${ }^{[12]}$. Sexual dysfunction following FGM is a national concern of human rights watchers ${ }^{[8]}$. Till the present date, there are very few neglected published studies in the literature to assess female sexual troubles following the genital mutilation. This study documents the presence of sexual dysfunction caused by FGM.

It is estimated that all around the world, FGM has been done to about 100-140 million regardless health risks and governmental punishments and that yearly 2 million girls are at risk of being mutilated for the fear of future adultery ${ }^{[1]}$. This assault predates Islamic times and is equally common among Africans regardless their religion ${ }^{[9]}$. According to many scholars of hadeeth like El Albany, that not even one true saying of the prophet nor even one verse of the holy Koran ordered for female genital mutilation ${ }^{[13]}$. In a matter of fact, according to most of Al-Azhar Islamic Scientists, it's not allowed in Islam to expose or touch any one's genitals except in emergency situations and not allowed to change any of god's creation by cutting any part of the body except if willed by the person herself to relief a discomfort ${ }^{[14]}$. There are several degrees of FGM in the Middle East and parts of Africa, classified into types (I, II, III and IV). Type I which included removal of the prepuce with or without part or the entire clitoris previously called Sunna circumcision to imply the false weakly proved belief that it has been ordered by Islam. The use of the classification Sunna circumcision was intentionally avoided to prevent implying the false belief that it has been ordered by Islam $^{[2]}$. In fact, most scholars and Islamic authorities agreed that all degrees of FGM are condemned by Islamic faith and that true female Sunna circumcision does not exist in the real world as removal of minimal tissue of the prepuce would request the help of pediatric surgeon and anaesthesia which wasn't available back then ${ }^{[14]}$. Type II FGM is excision of clitoris with partial or total removal of the labia minor. Type III FGM is called infibulation or pharonic circumcision which is excision of part or all of the external genitalia as well as narrowing or stitching the vaginal opening. Finally, type IV is unclassified including all types of abuse as burning and cauterizing the clitoris and the surrounding tissue, pricking, piercing, incising clitoris and/or labia, stretching of clitoris or labia, cutting vagina (Gishri 
Cuts), spilling corrosive substances or herbs into the vagina. Acute and lifelong complications are surely documented by scientific evidence including ; shock, infection, psychological and sexual problems ${ }^{[2-5]}$.

Very few researches studied the psychological and sexual functions of females who have been mutilated because of not considering it an important issue by the society which lead to lay speculation ${ }^{[6,15]}$.

Our study is a continuation of an already started research comparing the sexual function of mutilated and non-mutilated women as emphasizing only the health risks of FGM. leads to medicalization of the assault and its acceptance ${ }^{[11,16,17]}$.

In this case-control study, we investigated the correlations of female sexual dysfunction in both mutilated and non-mutilated groups.

There were no statistically significant differences between the two groups in the desire score and pain score with $p$-value $(0.389$ and 0.432$)$, respectively. However, there were significant differences in the satisfaction and orgasmic score with p-value $<0.001$ for both showing anorgasmia in the mutilated group.

Our findings add to the existing literature important complications of FGM demonstrating sexual dysfunction among types I and II mutilation which are present among the population of Upper Egypt. This supports previous studies which found that complications like clitorial cysts, infection hemorrhage and later sexual dysfunction occur in the form of anorgasmia after sexual excitation and so pelvic congestion and depression because of difficulty of relieving the excitation phase.

In the study by Sharifa A. Sibiani, 130 sexually active women with FGM and 130 sexually active women without FGM attending the outpatient clinic were interviewed and asked to answer the Arabic translated version of the female sexual function index (FSFI) questionnaire after explaining the objective of the study and took consent. The results showed that there were no significant differences between the two groups in the desire score $3.6+/-1.1$ in those with FGM versus $3.7+/-1.2$ in the control group, which is consistent with our study ${ }^{[18]}$.

A study done by Nenneh Kalokoh and Eric Riedel, chief academic officer in Waldon University in 2017 Psychology Faculty, for $\mathrm{PhD}$ degree, included 12 women from Sierra Leone, all of them were mutilated. The results showed statements as it takes longer for them to reach orgasm if any page 102 and most of them accept mutilation for their daughters because they don't want more desire than they already have $\mathrm{e}^{[19]}$; a result which is consistent with this study.

A study done on 2011 by Mellisa Arneson, Bemedgi State University, in a political science senior thesis and the advisor Patrick Donnay documented that Egypt has the highest prevalence of $\mathrm{FGM}^{[20]}$ which supports our study.

A study done in 2011, by Kimonge Bochere Muma, School of Education, Kenyatta University, Gucha Country, Kenya, included following up school performance of a simple randomly chosen sample of 23 girls post mutilation. This study advocated that FGM has an impact on the level of education, number of days attended and academic performance with t-value of 2.58 at $95 \%$ significant level ${ }^{[21]}$, which is consistent with our study.

\section{LIMITATION}

Unfortunately, our study had some limitations. The major limitation is the degree of mutilation as the common types in Egypt are the first and second degrees. So for further studies regarding this issue, we recommend all degrees of FGM including women with infibulation or type III as well as type IV to be included in the coming researches.

\section{CONCLUSION}

In conclusion, findings of the current study, in addition to data from previous studies, suggest that FGM adversely affects the female sexual function and unlike the false beliefs that non-mutilated women have excessive desire and so liable for adultery which is one of the main causes of insistence on mutilation. On the contrary, non-mutilated women have less difficulty of reaching orgasm; the latent desire free stage is more easily reached and so could be even more protected from adultery. However, most mutilated ladies scored similar desire score as those without FGM, suffering from anorgasmia after sufficient sexual excitation and more difficulty in relieving the sexual tension gained during intercourse, needing further sexual relations to relief the discomfort which leads to pelvic congestion and psychological frustration. This greatly supports the previous researches of sexual dysfunction which may be caused by female genital mutilation.

\section{ACKNOWLEDGEMENTS}

We are grateful to all the patients who agreed to participate in the study. We also appreciate the 
cooperation of the staff in the outpatient department who tried their best to make this study possible.

\section{CONFLICT OF INTEREST}

There are no conflicts of interest.

\section{REFERENCES}

1. Female Genital Mutilation (1996): Report of a Technical Working Group, Geneva, 17-19 July 1995. Family and Reproductive Health. World Health Organization, Geneva; 1996

2. World Health Organization study Group on Female Genital Mutilation and Obstetric Outcome (2006): WHO collaborative prospective study in six African countries. Lancet. 2006; 367: $1835-1841$

3. Almroth, L., Elmusharaf S., El Hadi N., Obeid A., El Sheikh M.A., Elfadil, S.M., and Bergström S. (2005): Primary infertility after genital mutilation in girlhood in Sudan. Lancet. 2005; 366: 385-391

4. Rymer J. (2003): Female genital mutilation. Curr Obstet Gynecol. 2003; 13: 185-190

5. Rouzi A.A., Sindi O., Radhan B. and Ba'aqeel H. (2001): Epidermal clitoral inclusion cyst after type I female genital mutilation. Am J Obstet Gynecol. 2001; 185: 569-571

6. Toubia N. (1994): Female circumcision as a public health issue. New Engl J Med. 1994; 331: 712

7. Rosen R., Brown C., Heiman J., Leiblum S., Meston C., Shabsigh R. et al. (2000): The Female Sexual Function Index (FSFI): a multi-dimensional self-report instrument for the assessment of female sexual function. Sex Marital Ther. 2000; 26: 191-208

8. Watson M.A. (2005): Female circumcision from Africa to the Americas: slavery to the present. Soc Sci J. 2005; 42: 421-437
9. Jones S.D., Ehiri J. and Anyanwu E. (2004): Female genital mutilation in developing countries: an agenda for public health response. Eur J Obstet Gynecol Reprod Biol. 2004; : 144-151

10. Sims, Shireen Madani (2016): PreTest. $14^{\text {th }}$ edition. McGrawHill, 2016;306.

11. Toubia N.F. and Sharief E.H. (2003): Female genital mutilation: have we made progress. Int $\mathrm{J}$ Gynecol Obstet. 2003; 82: 251-261

12. Raina R., Pahlajani G., Khan S., Gupta S., Agarwal A., and Zippe C. (2007): Female sexual dysfunction: classification, pathophysiology, and management. Fertil Steril. 2007; 88: 1273- 1284

13. Sabiq, Sayid. (2011): Fiqh us-Sunnah. darketab, 2011;451.

14. Elawa, Mohammed Selim (2018): female genital mutilation. National population council, 2018;5.

15. Reyners M. (2004): Health consequences of female genital mutilation. Rev Gynecol Pract. 2004; 4: 242-251

16. Shabaan L.M. and Harbison S. (2003): Reaching the tipping point against female genital mutilation. Lancet. 2003; 336: 347-349

17. Sundby J. (2003): Female genital mutilation. Lancet. 2003; 362: S26-S27

18. Alsibiani SA, Rouzi AA. Sexual function in women with female genital mutilation. Fertility and sterility. 2010; 93(3):7224-.

19. Arneson M. Female Genital Mutilation: Policies to Encourage Abandonment. Political Science Senior Thesis, USA. 2011; 1-22.

20. Kimonge BH (2011): Influence of School Based Policies on Internal Efficiency in Public Day Secondary Schools in Nyatike Sub County, Kenya. Unpublished M. ED Thesis, Kenyatta University, 2011 